\title{
Non-lethal elephant population control methods: Summary of the first workshop of the Elephant Specialist Advisory Group of South Africa
}

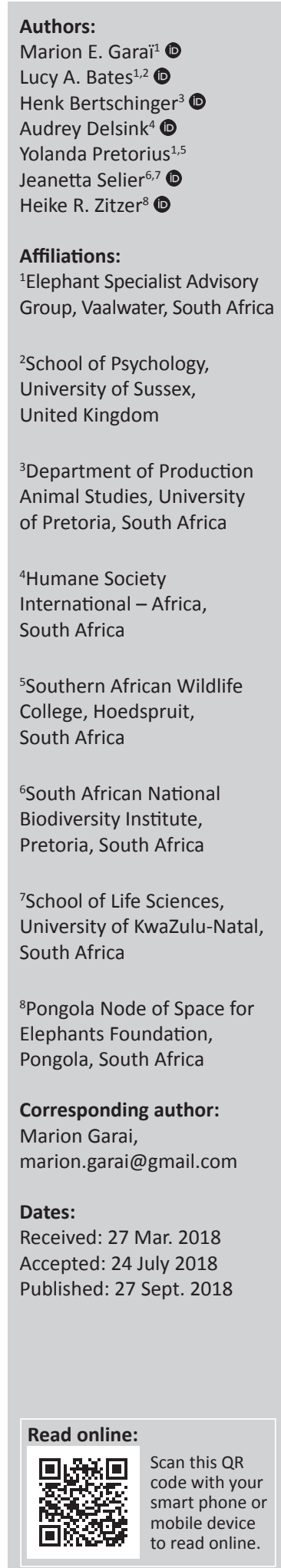

Management interventions are necessary to control elephant numbers within fenced wildlife reserves in South Africa. Use of non-lethal control methods is increasing, but information about their suitability and effects are not widely available. Three such methods are currently available: immunocontraception with porcine zona pellucida vaccine, vasectomy and gonadotropin-releasing hormone vaccine. Here we consolidate what we know about these methods, using published sources and material shared at a workshop held in South Africa in 2016, in order to provide up-to-date information for future policy decisions concerning the use of these methods in South Africa and elsewhere.

\section{Introduction}

Within South Africa, private ownership of wild animals is permitted (Blackmore \& Trouwborst 2018). Coupled with an improved ability to capture, transport, contain and manage large mammals, this has driven the introduction or reintroduction of elephants onto privately owned land: more than 800 elephants were translocated to existing or newly established state or privately owned fenced reserves between 1979 and 2001 as part of the efforts to reduce elephant numbers in Kruger National Park (Carruthers et al. 2008; Slotow et al. 2005). At present more than 21000 elephants are kept on 17 state-owned, (partially) fenced reserves, with approximately 7080 elephants held on privately or community-owned fenced reserves (Pretorius, Garaï \& Bates 2018).

Fenced wildlife reserves can be vulnerable to rapid or steep increases in elephant numbers (Mackey et al. 2006; Van Aarde et al. 2008). Management interventions are therefore often necessary to control or curb population increases, so that numbers remain within limits deemed acceptable by managers. Culling or translocation have traditionally been employed to immediately reduce elephant numbers, but these can evoke significant public criticism and/or may have significant impacts on the well-being of the remaining elephants (Dickson \& Adams 2009; Lötter et al. 2008; Slotow, Whyte \& Hofmeyr 2008; Van Aarde, Whyte \& Pimm 1999). As an alternative, non-lethal population control methods are increasingly being utilised, namely vasectomy, immunocontraception with porcine zona pellucida (PZP) vaccine or immunocastration with gonadotropin-releasing hormone $(\mathrm{GnRH})$ vaccine. These innovative methods do not directly reduce elephant numbers but can be adopted to suppress population increases by reducing reproduction rates. However, the suitability and long-term effects of these techniques on elephant physiology and behaviour are not yet fully or widely understood. Moreover, the long-term consequences of the techniques, both for the individuals who are treated and the wider social groups within the reserve, may be difficult to anticipate. Consequently, undue reliance is placed on the personal opinion and/or operational experience of individual elephant scientists, veterinarians and managers, and there appears to be considerable confusion about the function and utility of each method. There is a need, therefore, to document both scientific data and field experience, so that the collated information may direct further scientific study and form the foundation of appropriate future policy.

To this end, the Elephant Specialist Advisory Group of South Africa (ESAG) organised a workshop, the objectives of which were threefold:

- Firstly, to collate the best available information on the three non-lethal population control methods, summarising both the positive and negative aspects of each and defining gaps in our knowledge so that future research efforts can be suitably targeted.

How to cite this article: Garaï, M.E., Bates, L.A., Bertschinger, H., Delsink, A., Pretorius, Y., Selier, J., et al., 2018, 'Non-lethal elephant population control methods: Summary of the first workshop of the Elephant Specialist Advisory Group of South Africa', Bothalia 48(2), a2357. https://doi.org/10.4102/abc.v48i2.2357

Copyright: ( $)$ 2018. The Authors. Licensee: AOSIS. This work is licensed under the Creative Commons Attribution License. 
- Secondly, to determine how owners, managers and state authorities can be best supported to use this information to make appropriate, evidence-based decisions about which non-lethal control methods they could and should employ.

- And thirdly, to provide the collated information as a resource for inclusion into the National Norms and Standards for the Management of Elephants in South Africa (N\&S) (Government Gazette No. 30833, 29 February 2008).

All elephants within South Africa - whether owned privately or by the state - are subject to the stipulations laid out in the N\&S. However, the current document provides little guidance as to when and how to appropriately use the nonlethal methods now available. We aim to provide clear and objective guidelines on the use of these methods. Other management tools aimed at immediate population reduction (such as culling or translocation) were not addressed at the workshop. These have previously been well described (Balfour et al. 2007; Grobler et al. 2008; Slotow et al. 2008).

\section{Methods}

\section{Participants}

Elephant Specialist Advisory Group of South Africa convened the workshop in order to consolidate the latest information from ongoing research projects with both published data and the knowledge derived from the expertise and opinions of those working closely with elephants. Fiftyone delegates attended, comprising international scientists researching these techniques, elephant behaviour experts and representatives from national, provincial and local institutions charged with managing and conserving South Africa's elephants. All delegates have an interest in ensuring 'best practice' in the application of non-lethal population control methods. Delegates represented the following organisations: South African Department of Environmental Affairs (DEA); South African National Biodiversity Institute; South African National Parks; Eastern Cape Parks and Tourism Agency; Ezemvelo KwaZulu-Natal (KZN) Wildlife; Humane Society International - Africa; Limpopo Department of Economic Development, Environment and Tourism; Gauteng Department of Agriculture and Rural Development; Mpumalanga Tourism and Parks Agency; North West Parks Board; Tshwane University of Technology; University of KwaZulu-Natal; University of Pretoria; University of South Africa; Wildlife and Environment Society of South Africa; National Zoological Gardens.

\section{Programme}

To achieve the primary objective of the workshop, leading researchers in each of the non-lethal techniques were invited to present their latest data, with the following presentations: 'PZP immunocontraception and lack of behavioural responses' (Delsink 2016); 'Use and effects of GnRH vaccine on bulls' (Lueders 2016); and 'Effects of vasectomy on behaviour of bulls' (Zitzer 2016). These were followed by a final presentation, 'Anecdotes on possible behavioural implications of the three population control methods' (Pretorius 2016), introducing questions raised from a literature search and oral reports. This final presentation was intended to stimulate the subsequent discussions.

After the presentations, Professor Rob Slotow facilitated a discussion session, aimed at meeting the second and third objectives. All delegates were encouraged to consider two key questions: (1) what do you want to know about non-lethal control methods and (2) what is your primary motivation? Motivation is important because individual aims influence the perceived advantages and disadvantages of each method, and a method can only be deemed appropriate if its intended outcome is clear (e.g. aiming to preserve the habitat whilst avoiding lethal control). Delegates initially discussed these questions in small groups for $30 \mathrm{~min}$, with each group subsequently presenting their thoughts to the entire workshop, with time for questions and comments during and after each group's summary. The facilitator made notes during each summary and discussion using a flip chart, and the entire workshop was recorded using a Sony Dictaphone. The information from the presentations, published material and discussions were collated in Table 1, with recommendations for the use of each method summarised in Table 2.

\section{Results and discussion}

\section{Objective 1: Collate available scientific information summarising each method and define the remaining gaps in our evidence-based knowledge}

Porcine zona pellucida is an immunocontraceptive vaccine that is delivered by intramuscular injection to female elephants, usually via remote darting. The non-hormonal vaccine works to prevent pregnancy by stimulating antibodies against proteins vital for fertilisation (Kirkpatrick et al. 2012). It does not affect the hormone balance of the elephant (Delsink \& Kirkpatrick 2012). Studies have been measuring the efficiency and effects of PZP on elephant families and populations since 2000 (Delsink \& Kirkpatrick 2012), and success rates of at least $95 \%$ have been reported. The effects have been shown to be reversible over the current 16-year study period (Delsink 2016), with no side effects on pathology, histology or elephant behaviour so far having been noted (Delsink \& Kirkpatrick 2012; Delsink et al. 2013). Based on knowledge derived from this ongoing study (Bertschinger et al., submitted), this method can be considered an effective and safe way to limit elephant population growth, when it is part of a long-term, predefined management plan. However, PZP is not yet licenced by the Medicines Control Council for use in elephants in South Africa; therefore it can only be adopted as part of a registered study through the Department of Production Animal Studies, University of Pretoria, South Africa.

Vasectomies must be conducted under general anaesthetic by a specialist surgical veterinary team, and they result in permanent sterilisation of sexually mature males without 


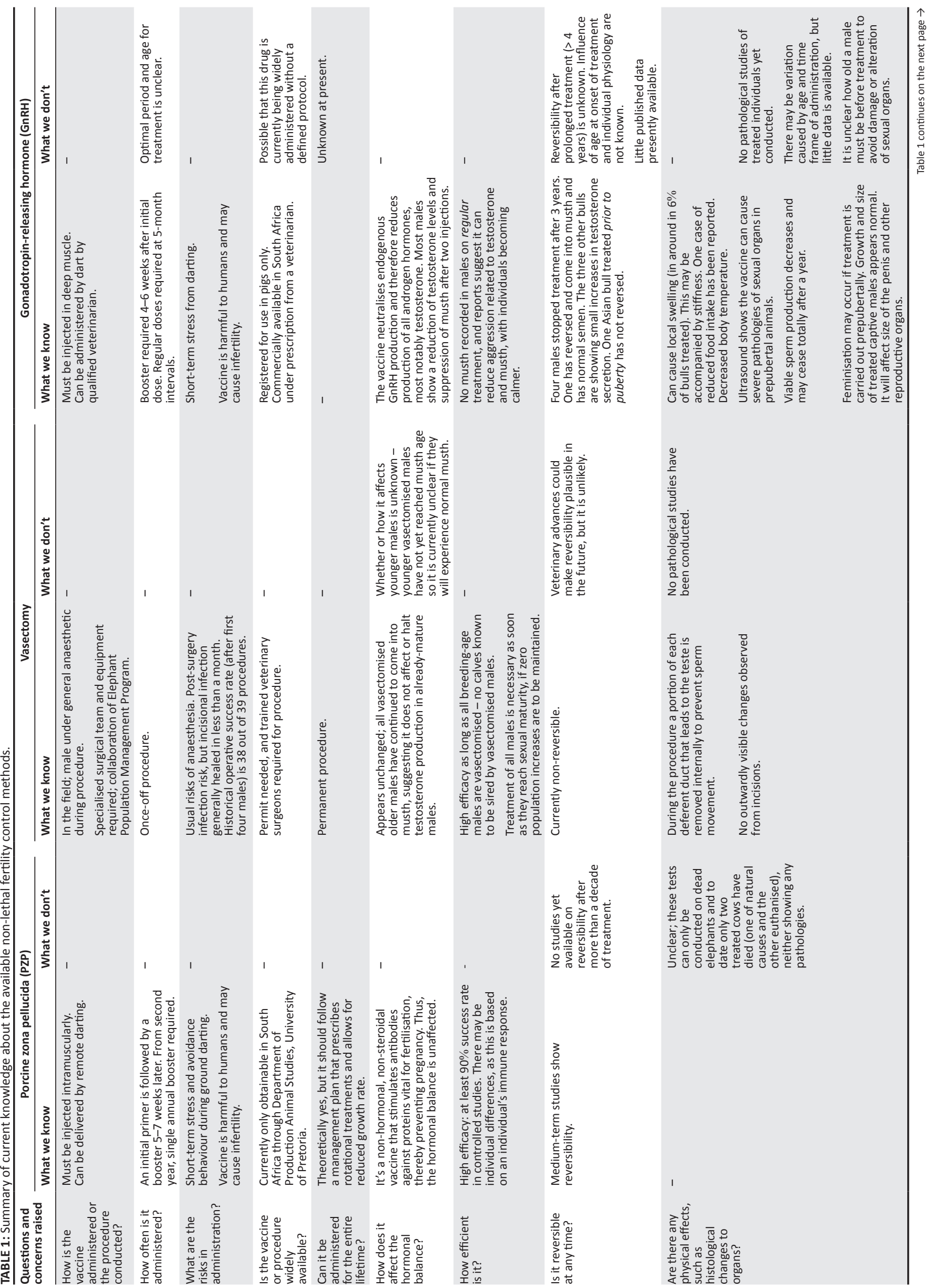



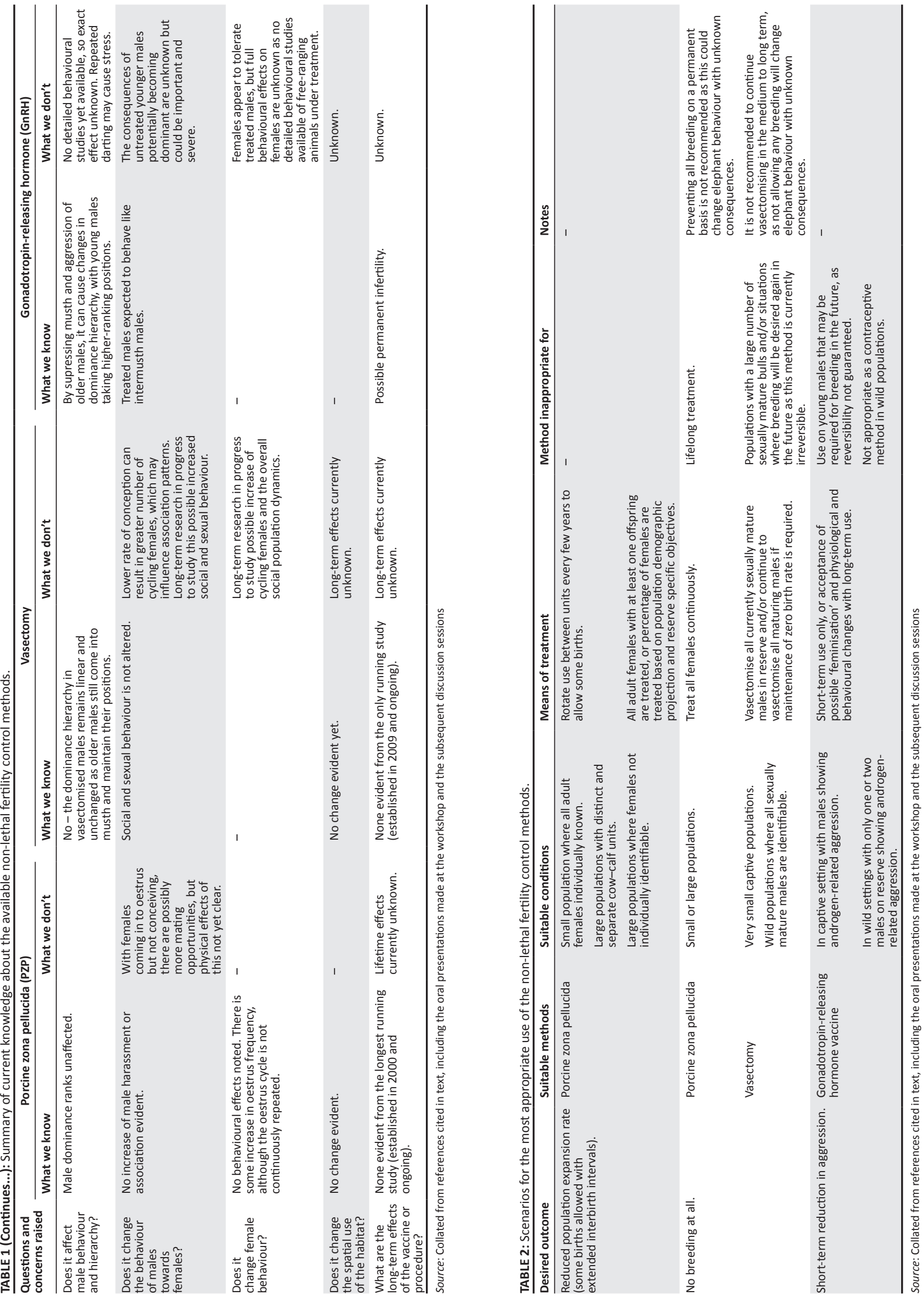
affecting testosterone production or musth cycling. The procedure has been performed on male elephants in several reserves across South Africa, but to date only one long-term ( $\geq 10$ years) monitoring and research programme exists, at the Pongola Game Reserve. Based on observations at this site, vasectomies do not appear to have any behavioural consequences for treated males (Zitzer \& Boult, in press). However, the effects on testosterone levels in younger males are not yet known and continuation of behavioural studies is required to identify any longer-term implications. This method of population control has not been tested for reversibility (D. Hendrickson [Colorado State University] pers. comm., 24 August 2017).

$\mathrm{GnRH}$ is a vaccine that is commercially available under prescription in South Africa, being currently registered for use in pigs. It neutralises endogenous GnRH and therefore reduces production of all androgen hormones, including testosterone (Bertschinger \& Scott Sills 2013). It has been studied in captive elephants, where males show a significant reduction of testosterone after the second booster (or third vaccination) (Lueders et al. 2014) and significant decrease of testicular and accessory sex gland sizes (Lueders et al. 2017). Reports from captive studies suggest it can reduce musth(testosterone-) related aggression (Bertschinger \& Scott Sills 2013), but further studies specifically measuring changes in musth aggression are required. Furthermore, its effects on wild (non-captive) elephants are not known. It is unclear if this method is reversible, or what duration of treatment is optimal if reversal may subsequently be required, but feminisation of males has occurred in those treated prepubertally (Lueders et al. 2014, 2017). Moreover, by altering musth and aggressive behaviour, this method could have direct impacts on the male dominance hierarchy and male behaviour (Doughty et al. 2014), although, again, detailed behavioural studies are lacking.

The information gained from the workshop presentations, discussions and published data were collated and summarised in Table 1. It was apparent from the workshop discussions that there were some key questions and concerns common to all three methods, specifically: (1) How is each method applied and what is the dosage? (2) What is the likelihood of success with each method? (3) Do the methods have any effects on elephant behaviour? (4) What are the (unintended) consequences of each method, in the short and long term? And (5) is the method appropriate for large populations? Table 1 at least partly answers most of these questions and clearly shows where more information is required.

\section{Objective 2: Determine how owners, managers and state authorities can be best supported to use this information}

When discussing the three methods, broader issues were also examined, principally concerning the benefits of each, in both the short and long term, to the environment and to the elephant population; their effects on the welfare of the elephant population; the economic implications of the control methods over both the short and long term; and how to best maintain the integrity of the whole ecological system, including maintaining or mimicking 'natural' gene flow. It was noted that all of these issues must be considered by individual properties before a method is adopted, and these are considered in Table 2, which summarises when each method might be most appropriately employed, based on current knowledge.

When asking the delegates to consider what they wanted to know about the methods, and what their motivation was, the facilitator directly asked participants how they could be helped to use the information that was being shared. One overwhelmingly popular suggestion was to develop a toolbox that could be used as a checklist by managers and state authorities to help them make appropriate decisions that take account of both the motivation (desired outcome) and available knowledge of the methods. The Trustees of ESAG agreed to take the lead in the process, and the toolbox will be based on the information set out in Tables 1 and 2 .

\section{Objective 3: Inform revisions of the relevant sections of the National Norms and Standards for the Management of Elephants in South Africa}

A short summary of the relevant points discussed, along with expanded copies of Tables 1 and 2 and all supporting documentation, were submitted to the DEA for inclusion in the N\&S revision process.

\section{Conclusion}

Following consideration of the information presented and the workshop discussions, the following recommendations are made: (1) PZP is the best studied and understood population control method. It has been shown to work effectively and studies so far indicate that it is reversible after medium-term use. We conclude it is the best method currently available to control increases in free-ranging elephant populations. (2) Vasectomy is an effective yet invasive and currently non-reversible method and therefore should only be adopted for use in free-ranging elephant populations after careful consideration. (3) GnRH vaccine should only be used on captive elephants, and only to reduce androgen-related aggression. Until further controlled scientific studies have been conducted, utilisation for reducing androgen-related aggression in free-ranging males should remain cautious and be temporary, following due consideration of all the potential side effects. Behavioural problems that are not related to androgens cannot be effectively treated with $\mathrm{GnRH}$. The use of GnRH as a contraceptive should be discouraged and/or halted until controlled studies have been conducted.

\section{Acknowledgements}

This workshop was generously hosted by the National Zoological Gardens, South Africa. Catering was funded by the Conservation Action Trust. We thank all delegates for 
attending and contributing their knowledge and opinions. We also express our gratitude towards Rob Slotow who chaired the discussions at the workshop.

\section{Competing interests}

The authors declare that they have no financial or personal relationships that may have inappropriately influenced them in writing this article.

\section{Authors' contributions}

M.G. conceived of and organised the workshop, assisted by Y.P. and L.B. Notes were taken at the workshop by L.B. who then prepared the manuscript, with M.G. Presentations were given by A.D., Y.P. and H.Z. at the workshop who also commented on drafts of this manuscript. H.B. and J.S. contributed to the discussions at the workshop, provided technical advice and commented on drafts of the manuscript.

\section{References}

Balfour, D., Dublin, H.T., Fennessy, J., Gibson, D., Niskanen, L. \& Whyte. I.J., 2007 'Review of options for managing the impacts of locally overabundant Africa Elephants,' IUCN/SSC AfESG, IUCN Gland, Switzerland, Cambridge, UK.

Blackmore, A. \& Trouwborst, A., 2018, 'Who owns and is responsible for the elephant in the room? Management plans for free-roaming elephant in South Africa', Bothalia - African Biodiversity and Conservation 48(2), 1-6. https://doi.org/ 10.4102/abc.v48i2.2271

Bertschinger, H.J. \& Scott Sills E., 2013, 'Contraceptive applications of GnRH-analog and vaccines for wildlife mammals of southern Africa: Current experience and future challenges', in E. Scott Sills (ed.), Gonadotropin-releasing Hormone (GnRH). Production, Structure and function, pp. 85-108, Nova Science Publications Inc, New York.

Bertschinger, H., Delsink, A., Van Altena, J.J. \& Kirkpatrick J., submitted, 'pZPImmunocontraception of African elephant cows: A review of 22 years of research' Bothalia: African Biodiversity \& Conservation Biology.

Carruthers, J., Boshoff, A., Slotow, R., Biggs, H., Avery G. \& Matthews, W., 2008, 'The elephant in South Africa: History and distribution', in R.J. Scholes \& K.G. Mennel (eds.), Scientific Assessment of Elephant Management in South Africa, pp. 23-83, Wits University Press, Johannesburg.

Delsink, A. 2016, 'PZP immunocontraception and lack of behavioural responses', Presentation at the first ESAG Workshop: Non-lethal elephant-population-control methods, 21st October 2016, National Zoological Gardens, Pretoria, South Africa.

Delsink, A. \& Kirkpatrick J.F. (Compilers), 2012, Free-ranging African Elephan Immunocontraception: A new paradigm for elephant management, Trident Press. Cape Town.

Delsink, A., Kirkpatrick, J., Van Altena, J.J., Bertschinger, H., Ferreira, S. \& Slotow, R. 2013, 'Lack of spatial and behavioural responses to immunocontraception application in African Elephants (Loxodonta africana)', Journal of Zoo and Wildlife Medicine 44, S52-S74. https://doi.org/10.1638/1042-7260-44.4S.S52
Dickson, P. \& Adams, W.M., 2009, 'Science and uncertainty in South Africa's elephant culling debate', Environment and Planning C: Government and Policy 27, 110-123. https://doi.org/10.1068/c0792j

Doughty, L.S., Slater, K., Zitzer, H., Avent, T. \& Thompson, S., 2014, 'The impact of male contraception on dominance hierarchy and herd association patterns of African elephants (Loxodonta africana) in a fenced game reserve', Global Ecology and Conservation 2, 88-96. https://doi.org/10.1016/j.gecco.2014.08.004

Government Gazette No. 30833 (29 February 2008), National Environmenta Management: Biodiversity Act (10/2004): National norms and standards for the management of elephants in South Africa, Department of Environmental Affairs, Pretoria, South Africa.

Grobler, D., Van Altena, JJ., Malan, J. \& Mackey, R. 2008, 'Elephant Translocation', in R.J. Scholes \& K.G. Mennell (eds.), Scientific assessment of elephant management in South Africa, pp. 241-256, Wits University Press, Johannesburg.

Kirkpatrick, J.F., Delsink, A., Van Altena, J.J. \& Bertschinger, H.J., 2012, 'Fertility control and African elephants: A new paradigm for management', in M. Aranovich \& O. Dufresne (eds.), Elephants: ecology, behaviour and conservation, pp. 77-96, Nova Science Publications Inc, New York.

Lötter, H.P.P., Henley, M., Fakir, S. \& Pickover, M., 2008, 'Ethical considerations in elephant management', in R.J. Scholes \& K.G. Mennell (eds.), Scientific Assessment of Elephant Management in South Africa, pp. 406-445, Wits University Press, Johannesburg.

Lueders, I., 2016, 'Use and effects of GnRH vaccine on bulls', Presentation at the first ESAG Workshop: Non-lethal elephant-population-control methods, 21st October 2016, National Zoological Gardens, Pretoria, South Africa.

Lueders, I., Hildebrandt, T.B., Gray, C. Botha, S., Rich, P. \& Niemuller C., 2014 'Suppression of testicular function in a male Asian elephant (Elephas maximus) treated with Gonadotropin-Releasing Hormone vaccines.' Journal of Zoo and Wildlife Medicine 45(3), 611-619. https://doi.org/10.1638/2013-0233R.1

Lueders, I., Young, D., Maree, L., Van der Horst, G., Luther, I., Botha, S. et al., 2017, 'Effects of GnRH vaccination in wild and captive African Elephant bulls (Loxodonta africana) on reproductive organs and semen quality', PLoS One 12(9), e0178270. https://doi.org/10.1371/journal.pone.0178270

Mackey, R., Page, B., Duffy, D. \& Slotow. R. 2006, 'Modelling elephant population growth in small, fenced, South Africa reserves', South African Journal of Wildlife Management 36, 33-43.

Pretorius, Y., 2016, 'Anecdotes on possible behavioural implications of the three population control methods', Presentation at the first ESAG Workshop: Non-lethal elephant-population-control methods, 21st October 2016, National Zoological Gardens, Pretoria, South Africa.

Pretorius, Y., Garaï, M. E. \& Bates, L.A., 2018, 'The status of African elephant (Loxodonta africana) populations in South Africa', ORYX. https://doi.org/10.1017/ S0030605317001454

Slotow, R., Garaï, M. E., Reilly, B., Page, B. \& Carr, R. D., 2005, 'Population dynamics of elephants re-introduced to small fenced reserves in South Africa' South African Journal of Wildlife Research 35(1), 23-32.

Slotow, R., Whyte, I. \& Hofmeyr, 2008, 'Lethal management of elephants', in R.J. Scholes \& K.G. Mennell (eds.), Scientific Assessment of Elephant Management in South Africa, pp. 370-405, Wits University Press, Johannesburg.

Van Aarde, R., Whyte, I. \& Pimm, S., 1999, 'Culling and the dynamics of the Kruger National Park African elephant population', Animal Conservation 2, 287-294. https://doi.org/10.1111/j.1469-1795.1999.tb00075.x

Van Aarde, R., Ferreira, S., Jackson, T. \& Page, B., 2008, 'Elephant population biology and ecology', in R.J. Scholes \& K.G. Mennell (eds.), Scientific Assessment of Elephant Management in South Africa, pp. 84-147, Wits University Press, Johannesburg.

Zitzer, H.R., 2016, 'Effects of vasectomy on behaviour of bulls', Presentation at the first ESAG Workshop: Non-lethal elephant-population-control methods, 21st October 2016, National Zoological Gardens, Pretoria, South Africa.

Zitzer, H.R. \& Boult, V.L., in press, 'Vasectomies of male African elephants as a population management tool: Case study', Bothalia African Biodiversity and Conservation. 